\title{
Por la dignidad del deudor
}

Jesús María Sanguino Sánchez

"Estoy armado de valor y preparado para mi suerte.

Dadme vuestra mano, Bassanio ¡Adios!

No sintáis que me haya ocurrido esa desgracia por vos, pues en esta ocasión la fortuna se ha mostrado más compasiva que de costumbre. Es su hábito dejar al desdichado sobrevivir a su riqueza para contemplar con ojos huecos y arrugada frente una pobreza interminable. Pues bien ella me libra del lento castigo de semejante miseria».

(El Mercader de Venecia - William Shakespeare).

\section{I.- Introducción}

La humanidad se divide y se ha dividido siempre en dos grupos: los deudores y los acreedores.

Hay hombres y mujeres psicológicamente caracterizados por ser permanentes deudores. Siempre creen estar en deuda con los demás. Son generosos, siempre están dando cosas, afectos, atenciones, sin recibir nada a cambio. Otros son constitutivamente acreedores, siempre están esperando que los demás le satisfagan sus deseos, consideran que no se les concede, atienden o quieren como ellos esperan. Son seres insatisfechos, egoistas.

Los niños, generalmente corresponden al grupo de permanentes acreedores. Nuestra cultura latina, machista, en la relación de pareja, la mujer es la permanente acreedora y el hombre su eterno deudor.

Las religiones y las ideologías también van moldeando esta estructura de relación. El calvinismo considera la riqueza y el éxito, una benevolencia de la divinidad para formar el círculo de los elegidos. Los elegidos, los ricos y poderosos ven al pobre siempre como su permanente deudor. La 
idea cristiana, de soportar la pobreza, la miseria en este mundo con la esperanza de encontrar el premio después de la muerte, ha creado una legión de adeptos eternamente deudores. La estirpe calvinista de las instituciones jurídicas de Estados Unidos, ha convertido a los norteamericanos en los cultores de la riqueza y el desprecio hacia los pobres. Las relaciones de EE.UU. con esta mestiza y empobrecida Latinoamérica nos ha convertido en los eternos deudores.

Martirizada relación de poder, en la que siempre estamos a la voluntad del acreedor, la deuda y el crédito entran a formar parte de la lógica del poder. La clase vencedora subyuga a la vencida, el deudor siempre está a merced del acreedor. Es el juego del poder y la fuerza entre el gato y el ratón, que tan maravillosamente describe Elías Canetti:

«El ratón una vez atrapado, está bajo el régimen de fuerza del gato; este lo agarró, lo mantiene apresado, su intención es matarlo. Pero apenas comienza a jugar con él, agrega algo nuevo lo suelta y le permite correr un trecho. No bien el ratón se vuelve y corre, escapa de su régimen de fuerza. Pero está en el poder del gato de hacerle regresar. Si le deja irse definitivamente, lo ha despedido de su esfera de poder.

Dentro del radio en que puede alcanzarlo con certeza permanece en su poder. El espacio que el gato controla, los vislumbres de esperanza que concede al ratón, vigilándolo meticulosamente, sin perder su interés por él por su destrucción; todo ello reunido -espacio, esperanza, vigilancia e interés destructivo- podría decifrarse como el cuerpo propiamente dicho del poder o sencillamente como el poder mismon. ${ }^{1}$

El deudor al decir de Carbonniere:

«Es el tipo ingrato a primera vista, pues el derecho de los créditos y las deudas, habla menos al espíritu que el derecho de las personas y de familia". ${ }^{2}$

1 Elías Canetti, Masa y poder; Muchnik editores, Barcelona, $3^{\circ}$ edición, 1981, p. 277.

2 Jean Carbonniere, Derecho flexible, Ed. Tecnos, Madrid, 1974, p. 287. 
La relación jurídica entre el deudor y el acreedor, crea un mecanismo por el cual el primero se liga al segundo a través de un elemento "misterioso", es la entrega de la libertad. El deudor se vuelve un esclavo de su acreedor.

En el libro de los Proverbios 22-7, se lee:

"El rico manda al pobre; y quien toma prestado se hace siervo de aquel que le prestan.

El derecho se ha encaminado insaciablemente a crear procedimientos, procesos, estatutos que protegen al acreedor, que le permiten recuperar lo prestado, aun en detrimento de los derechos y la persona del deudor; es lo que la historia nos presenta.

Es la historia de la deshumanización del derecho de los créditos, creado por las clases dominantes, por los mercaderes, por los banqueros, por los usureros, por los grandes grupos económicos que no permiten que el deudor perturbe, con sus incumplimientos, el sistema creado para sus intereses económicos y jurídicos.

\section{El deudor en la literatura}

La situación del deudor frente a su acreedor ha logrado plasmar en la literatura todo su desgarramiento, su vulnerabilidad, su angustia.

En el epígrafe de este trabajo, se transcribe la manifestación de Antonio en el juicio de ejecución instaurado por el Judío Shylock para obtener el cumplimiento de las obligaciones contraídas por el préstamo dado a su amigo Bassanio, Antonio debía pagar con una libra de carne de su cuerpo, el incumplimiento de las obligaciones.

Shakespeare, en su obra el "Mercader de Venecia", estudiada por muchos juristas, rescata el derecho a la dignidad del deudor incumplido quien prefiere la tortura, el atentado a su integridad física en manos de su acreedor. Para Antonio es preferible entregar una libra de carne de su cuerpo, antes que soportar la indignidad de la miseria, la ruina de sus negocios. Al decir de Carboniere, en el «Mercader de Venecia», se perfila el tipo del deudor moderno, el deudor comercial de obligaciones dinerarias. Es también el retrato del acreedor moderno, el banquero inclemente, arrasador, sin compasión ni miramiento alguno. 
Honorato de Balzac, sufre en su propia persona la estigmatización de ser bancarrotado. En su "César Birottean" no hace más que trasladar en su personaje, sus sentimientos, sus quejumbres, su desgracia de ser perseguido por sus acreedores. Nadie ha podido describir mejor la psicología del deudor que Balzac.

Mientras los negocios del deudor sean prósperos, mientras esté cumpliendo con sus acreedores será bien acogido, elogiado por los bancos; cuando vienen las dificultades, cuando el deudor no puede honrar sus obligaciones, a los ojos de sus acreedores se vuelve un ser despreciable, un réprobo.

Birottou describe con precisión jurídica el procedimiento de quiebra, es la tragedia de la probidad, es el retrato de la sociedad comercial floreciente de la mitad del siglo XIX, es al decir de Carboniere: «Es el reino del dinero. El emprendedor siglo XIX supo darle la vuelta a la institución de la deuda y hacer un instrumento de servidumbre un medio de conquista. Promesas de venta, letras de cambio, descuentos, el libro está atravesado por todas las fatuas mayorías jurídicas, por medio de las cuales los hombres de la civilización monetaria tienden los puentes hacia el futuro. César Birottou, rodó por este tumulto de derecho mercantil». ${ }^{3}$

\section{El deudor y el derecho}

Desde la época del Derecho romano, todas las leyes se han concebido y se han venido elaborando en beneficio del acreedor. Durante más de siete siglos, el acreedor adquirió el derecho de persecución sobre la persona del deudor para disponer de su vida o de su libertad, como forma de satisfacer las obligaciones adquiridas.

En los inicios del derecho romano, las relaciones entre acreedores y deudores se soportaron sobre una concepción religioso-jurídica. Las obligaciones nacían bajo el patrocinio y protección de la divinidad; los incumplimientos del deudor no solo constituían una infracción jurídica sino una violación de lo acordado frente a la divinidad.

Es necesario resaltar la naturaleza jurídica del patrimonio, el que se consideraba como parte de la persona humana, era una emanación de la personalidad, de ahí que el derecho del acreedor sobre su deudor se dirigía

3 Jean Carbonniere, op.cit., p. 290. 
contra la persona física, el que por afección atraía su propio patrimonio para el cumplimiento de sus obligaciones.

$\mathrm{El}$ acreedor tenía el derecho de perseguir físicamente a su deudor disponiendo de su libertad o de su vida como se consagró en la Ley de las XII Tablas.

La ejecución se desarrollaba a través de la «manus injectio», al deudor juzgado por el juez se le concedía un plazo de treinta (30) días para cumplir la sentencia de pago. Transcurrido este plazo, si el deudor no cumplía con la sentencia del juez, el acreedor se apropiaba de la persona física de su deudor y lo volvía prisionero de sí, para que el pretor se lo adjudicara como un bien propio.

Con la aprehensión física del deudor, al acreedor se le facultaba para amarrar a su deudor, para encadenarlo; la retención duraba sesenta (60) días, al cabo de los cuales, se le llevaba a los mercados públicos por tres días para que alguien redimiera sus deudas.

Si el pobre deudor no tenía la fortuna de conseguir un familiar o un amigo que le cancelara la deuda, el acreedor quedaba autorizado para disponer de la vida del deudor, descuartizándolo o convirtiéndolo en un esclavo mediante la venta "tras Tiber".

Si existía una pluralidad de acreedores, la ejecución se realizaba con el descuartizamiento del deudor, cuyas partes se repartían entre sus acreedores en proporción al monto de sus créditos. La institución de la "partis secandon no señala si las partes del cuerpo del deudor tenían el mismo valor, o si alguna de ellas era de significativa importancia.

Algunos historiadores señalan que en ningún caso se efectuó la sentencia de descuartizamiento del deudor. Aunque existía la institución, ella tenía como finalidad servir de medio intimidatorio.

Bajo la vigencia de la Ley de las XII Tablas, se generaron excesivos endeudamientos a la par que, reiterados incumplimientos, lo que multiplicó las multiplicidad de ejecuciones individuales que incrementaron considerablemente el número de esclavos adquiridos por los acreedores insatisfechos.

La crueldad de la Ley de las XII Tablas, la inhumana persecución de los acreedores contra los deudores incubó necesariamente el malestar de la sociedad y una revuelta popular presionó la reforma de la Ley de las XII Tablas.

La revuelta tiene su origen en un hecho generador, que va a exacerbar los ánimos de la multitud. Tito Livio, en las «Décadas de la historia 
romana» citado por Cervantes Ahumada, trae el siguiente pasaje histórico que sirvió como detonante a la revuelta popular.

«En este año, el pueblo romano recibió en cierta manera una libertad nueva con la abolición de la servidumbre por deudas, este cambio en el derecho se debió a la infame pasión y tremenda crueldad de un usurero llamado L. Papirio. Este retenía en su casa a C. Publilio que se había entregado para rescatar las deudas de su padre. La edad y belleza del joven, que debía excitar su pasión, solo sirvieron para inflamar su inclinación al vicio y al libertinaje más odiosos. Considerando aquella flor de juventud como aumento de su crédito, trató primeramente de seducirle con obscenas palabras; y después como Publilio, despreciándole no daba oído a sus impúdicas palabras, trató de asustarle con amenazas, poniéndole constantemente delante de los ojos su espantosa miseria: al fin, viendo que piensa más en su condición de hombre libre que en su situación presente le hace desnudar y azotar con varas. Lacerado el joven por los golpes consigue escapar por la ciudad, que llena con sus quejas contra la infamia y crueldad del usurero; la multitud, que se había engrosado compadecida por su juventud, indignada por el ultraje, animada también por la consideración de lo que le aguarda, tanto a ella como a sus hijos, marcha al foro y desde allí se dirige precipitadamente hacia la Curia. Obligados los cónsules por aquel tumulto imprevisto, habiendo convocado al Senado, a medida que los Senadores entraban, el pueblo se arrojaba a sus pies, mostrándoles el lacerado cuerpo del joven. Por el atentado y violencia de un solo hombre, aquel día quedó roto uno de los lazos más fuertes de la fe pública. Los cónsules recibieron órdenes de proponer al pueblo que en adelante ningún ciudadano podría, sino por pena merecida y esperando el suplicio, quedar sujeto con cadenas o grillos; de la deuda deberían responder los bienes y no el cuerpo del deudor. Por esta razón pusieron en libertad a todos los detenidos por deudas y se tomaron disposiciones para que en adelante ningún deudor pudiese ser reducido a prisión»."

Los abusos de los acreedores y la revuelta popular, condujeron a los cónsules a modificar la Ley de las XII Tablas, para crear una de las normas

4 Raúl Cervantes Ahumada, Derecho e quiebras, Ed. Herreros S.A., México, 1978, p.21. 
más trascendentales en el derecho de ejecución. La «lex poetelia papiria», expedida en el año 441, en la que se sustituyó el sujeto de la persecución en la persona del deudor para instaurar las acciones del acreedor solamente contra su patrimonio.

Esta ley consagró el estatuto de la "pignoris capio» por el cual los acreedores tomaban todos los bienes de su deudor, sin limitación alguna para constreñirlo a cancelar todas sus obligaciones.

Con esta disposición los acreedores seguían cometiendo abusos contra el deudor, lo que obligó a reformar la ley, mediante una nueva Ley Hortensia, expedida por la opresión de las multitudes que pedían un cambio de la ley "lex poetelia papiria», en razón de los abusos cometidos por los acreedores. En el año 737, se expidió la "Lex Julia» que renovó el procedimiento de ejecución; en ella se introdujeron dos figuras que van a perdurar a través de los siglos: «la bonorum venditio» que consistía en realizar la venta en bloque de todos los bienes del deudor y la «bonorum cessio» o sea la cesión voluntaria de los bienes. La bonorum cessio desapareció cuando el procedimiento formulario dejó de regir, se sustituyó por la "distractio bonorum», cuando los bienes se vendían en detalle y a través del denominado curador. "Al curador bonorum, se le señalaba la función de administrar provisionalmente los bienes del deudor, según facultad concebida por el Edicto de Rutilio Rufo, del año 118 a.C. Esta institución, vislumbra dos órganos que pasarán a la historia del derecho concursal, la conformación de la masa de la quiebra y la sindicatura, junto con la aparición del desapoderamiento de los bienes del deudor. Este curador era nombrado por la mayoría de los acreedores, y su gestión terminaba cuando expiraba el término de publicidad con el decreto del magistrado que ordenaba la posesión de los bienes del deudor por los acreedores.

El magister bonorum era nombrado por todos los acreedores del deudor, sus funciones, que hoy día corresponden al sindico, consistían en realizar un inventario completo de los bienes, de terminación de las deudas, proposición concreta de la forma de liquidación de las deudas con el acervo patrimonial y la venta en pública subasta de los bienes.

Las atribuciones de ambos funcionarios estaban interrelacionados, siendo posible distinguir tres periodos en que se desarrolla: a) Antes de entrar en posesión; b) en posesión del cargo, y c) al cesar este. 
En la primera etapa debía prestar juramento de desempeñar fielmente su cometido (lo cual se ha mantenido a través del tiempo) y otorgar caución. Esta última podría ser personal, por terceros o constituyendo algún derecho real de prenda o hipoteca.

Las funciones que se comprenden dentro de la segunda etapa fueron: inventariar y administrar los bienes del fallido; el logro de la renta; recuperar los bienes o efectos en poder del deudor o terceros; ejercer la acción de cobrar los créditos activos y promover las acciones paulinas o de nulidad contra los actos del deudor en fraude a sus acreedores. Finalmente en la última etapa debía rendir cuenta documentada de su administración.

El curador bonorum, era responsable por sus actos, tanto por dolo o por culpa, siendo pauta de su conducta de vida a la diligentia quam in suis rebus. Pero no existía una sanción específica para el funcionario que había desempeñado mal el cargo. Las sanciones estaban en relación con degradaciones al honor civil, lo que traía aparejada la capitis disminutio, dentro de las tres posibilidades punitivas: máximo, media y mínima.

La infamia, como sanción estaba vinculada específicamente al derecho de los pretores para reprimir las conductas ilícitas con una amplia gama de posibilidades punibles. La sanción mediata requería juicio previo y se aplicaba a los supuestos de administración incorrecta del patrimonio del menor o de la mujer, siendo impuesta a dichos funcionarios por indebido desempeño de la comisión.

En la institución de la bonorum distractio, se encuentra un curador, al cual le corresponde la venta de los bienes en detalle, sin ingerencia de la autoridad, y sin necesidad de pública subasta. El procedimiento de la bonorum distractio presenta con la quiebra y el concurso moderno, mayores analogías que la bonorum venditio. En efecto, a fin de asegurar la comparecencia de todos los acreedores, se estableció un término de dos años para los acreedores presentes (de la misma provincia) y de cuatro para los ausentes, de otras provincias. La administración de los bienes por el curador bonorum era, pues, prolongada y su designación se efectuaba por el juez a propuesta de la mayoría de los acreedores. Como ya habíamos dicho, el curador realizaba la venta de los bienes sin intervención del juez, pero tenía el control de los acreedores y con la obligación de declarar bajo juramento que había procedido honestamente. 
Con la caída del Imperio romano, desaparecen las instituciones de la ejecución colectiva, los nuevos pueblos de conquistadores asumen la dirección jurídica del pueblo conquistado". 5 .

Con el término del Imperio romano los nuevos conquistadores regresan al proceso de ejecución contra la persona del deudor, es el regreso a la Ley de las XII Tablas, era una mezcla del derecho romano y la ley del conquistador. El invasor llevaba su propio derecho, el que mezclaba con el derecho de las ciudades conquistadas, era una simbiosis entre el derecho romano, el canónico y el derecho local.

En el derecho de los bárbaros se le facultaba al acreedor para secuestrar los bienes de su deudor, sin que mediara la autorización judicial; luego ante el magistrado se surtía una actuación, una especie de conciliación, en la que el deudor se comprometía a pagar las obligaciones vencidas a su acreedor; en el evento que no cumpliera la promesa, se secuestraban los bienes o la persona del mismo deudor. Se vuelve a la ejecución personal, se consagra en este interregno, lo que más adelante se va a constituir como un principio inalterable de la ejecución: quien es primero en el tiempo, lo es en el derecho. El privilegio del primer ejecutante es un aporte a la historia del derecho de esta época histórica, quien ejecuta primero es quien cobra.

En la Edad media, nace a la vida jurídica un nuevo derecho, el derecho comercial, su origen se remonta en las celebres comunas de la baja edad media. El desarrollo de la actividad comercial en las costas del Mediterráneo, el desarrollo de las ferias, va formando el derecho de los negocios con estatutos autónomos, independientes del derecho civil.

El desarrollo del comercio apareja la creación de instituciones como la "banca rota» una figura concursal, ubicada en los sistemas jurídicos como una ejecución colectiva o universal.

En sus inicios, la quiebra se extendió para los comerciantes y para los no comerciantes, como lo señalaba el estatuto de la Siena del año 1692; posteriormente, el estatuto quebrario quedó restringido a los comerciantes pues eran los que operaban masivamente y adquirían créditos cuyos incumplimientos generaban reacciones en cadena perturbadoras de la actividad mercantil.

5 Jesús María Sanguino Sánchez, «Un derecho concursal para el futuro», en: Derecho concursal argentino iberoamericano, Ed. Ad-hoc, Tomo III, Buenos Aires, p. 145. 
El nacimiento del derecho comercial dio lugar a la creación de una jurisdicción propia para resolver los conflictos de y para los comerciantes.

En el caso de la ejecución universal, cada ciudad tenía su propio estatuto para regular los procedimientos de ejecución universal.

La mayoría de los estatutos contenían disposiciones crueles, infamantes que colocan a la persona del deudor como sujeto de las más injustas y crueles represalias. Eran penas aflictivas, severas, los comerciantes que incumplían sus obligaciones se les consideraban ladrones y como ladrones eran tratados; de ahí la detención física de la persona, privándolo de su libertad, en algunos estatutos se consagraba el derecho de los acreedores para dar muerte a su deudor; igual que la aprehensión física y la muerte, también se consagró el denominado "bando", que consistía en la publicación del nombre del fallido en las paredes de las comunas con el cual quedaba marginado de cualquier amparo de protección legal. Se le arrodillaba en su dignidad, se le despojaba de todos sus derechos, cualquiera podía agredirlo en su persona y sus bienes y hasta podía matarlo sin consecuencias para el agresor. El "bando" excluía al fallido de todas las actividades de la sociedad civil; le estaba prohibido contratar los servicios de abogados y defensores.

La detención física del deudor fallido la hacían los propios acreedores, quienes posteriormente lo sometían a la autoridad competente; pero además de las penas de detención física, el "bando" permitía la muerte, se autorizaban las torturas para que el deudor confesara sobre sus actividades, sobre sus bienes, sobre sus cómplices. La tortura se convirtió en un medio de prueba y no solo se practicaba al deudor sino también a sus amigos y familiares.

Pero además de todas estas penas y torturas, se establecieron otras medidas de publicidad infamante "se pintaba la imagen del fallido en los edificios públicos, en las comunas para que todos los analfabetas lo reconocieran». Este medio de publicidad aún perdura en los procedimientos actuales como es el de mantener el nombre del deudor en los bancos de datos; en forma indefinida, es el nuevo ritual informativo que atenta contra la dignidad de la persona humana.

También la publicidad se hacía a través de otros mecanismos, como el registro del fallido en la picota pública, que consistía en amarrarlo a un árbol o a un poste y exponerlo al escarnio público o trasladándolo en jaula, totalmente desnudo acompañado de procesiones rimbombantes, solemnes y crueles. 
Adicionalmente se producía una «capitis diminutio», al deudor fallido se le prohibía ejercer el comercio, perdía los derechos políticos, y se prohibía ejercer cargos públicos, lo que también se cumplía con los hijos del deudor.

Para morigerar el sistema de la bancarrota, se buscó una institución intermedia que evitaba la quiebra del deudor, fue la institución de la "bonorum Cessio», incorporada en la Lex Julia, por la cual el deudor de buena fe, estaba facultado para entregar los bienes a los acreedores a fin de cancelar todas sus obligaciones.

En la edad media, esta figura de la cesión de bienes se incorporó al derecho de quiebra, como una medida cautelar de la misma, pero de unas características humillantes para los comerciantes fallidos.

Examinemos como se cumplía esta institución, como descriptivamente lo hacen los profesores Maffia:

«Diversas regulaciones, tanto en Italia como en Francia, indicaban minuciosamente los pasos en que consistía el procedimiento de cesión de bienes: el deudor era conducido desde el palacio comunal hacia la plaza pública, habitualmente precedido por un trompetero y seguido por un cortejo de chiquillos que saltaban, gritaban y reían, agitando bolsas vacías, símbolo de pobreza. Cuando era inevitable, una jauría alborotada por el bullicio de los chicos los acompañaba con sus ladridos. Así llegaba el deudor a la plaza donde los acreedores y la población curiosa disfrutaban del espectáculo. Una vez en la plaza el deudor debía aproximarse a una piedra colocada especialmente a ese fin, llamada "piedra del vituperio", y allí, despojado de sus ropas, se exhibía desnudo ante los espectadores como demostración de que con nada se quedaba (de donde la expresión, que aún perdura, "se quedó con una mano atrás y otra adelante" para referirse a quien perdió todos sus bienes). Pero no terminaba allí la humillación del cedente: el extremo máximo lo constituía lo que los estatutos llamaban acculattata: el deudor, desnudo, debía dejarse caer sentado por tres veces sobre la piedra del vituperio, al tiempo que proclamaba que todo su haber era cedido a los acreedores.

Aun con eso la humillación del cedente no había concluido, pues estaba obligado bajo pena de prisión a llevar de por vida un gorro verde o del color que consignaran los estatutos: el verde prevalecía en Francia; en Venecia debía ser rojo si el quebrado era judío. Otras ciudades lo ordenaban de color amarillo o blanco, a veces con la efigie de un zorro -símbolo de malicia-. Por último, diversas prohibi- 
ciones -portar armas, vestir prendas finas, ocupar cargos públicoscompletaban su inequívoca capitis deminutio. En buena medida los cedentes estaban asimilados a los fallidos.

Las referencias precedentes demuestran que en la época examinada no se habían animado a derogar el régimen de la cessio romana, pero tampoco disimulaban la poca disposición hacia el instituto. Va de suyo que quienes recurrían a ese remedio, ya habían agotado las fórmulas imaginables para evitar o demorar la quiebran. ${ }^{6 .}$

\section{El deudor y la religión}

Las relaciones entre el acreedor y el deudor, a lo largo de la historia de la humanidad se han caracterizado por el abuso del poder del primero contra el segundo, por las instituciones jurídicas creadas y perfeccionadas a favor del acreedor, por la permanente y constante humillación del deudor incumplido; por los tratos degradantes, por las infamias sin fin, razón que condujo a las religiones a tomar partido en esta lucha desigual.

Los textos bíblicos han servido de soporte para que las religiones se manifestaran sobre esta eterna y desigual relación entre deudor y acreedor.

Los principios bíblicos están orientados hacia la protección de los deudores y sus familias. Ni pena de reclusión, ni atentados contra la vida, ni ninguna restricción, la libertad del deudor es aceptada como medio para cobrar deudas.

En el Deuteronomio 24: 10,11, 12 y 13, se consagra:

"Si prestas algo a tu prójimo no entrarás en su casa para tomar prenda, esperarás fuera de ella a que el deudor te saque fuera la prenda". «Si este es pobre no te acostarás sobre la prenda, se la devolverás al ponerse el sol para que el se acueste sobre su vestido y te bendiga, y este será para ti justicia ante el Señor tu Dios».

La iglesia condena las operaciones de los acreedores, en las que se establezca usura. La iglesia supone que siempre que exista el pago de un interés, hay una usura; por eso la prohibición de conceder créditos.

6 Osvaldo J. Maffia y María Ofelia de Maffia, Legislación concursal, Víctor Zavalia editor, Buenos Aires, 1979, pp. 44, 46-47. 
La condena a la usura se soporta sobre los textos bíblicos, unos del Antiguo Testamento, otros del Nuevo Testamento. Se toma del Deuteronomio XXIII: 19, 20, del Éxodo XXII: 25, y del Levítico XXV: 35, 36 y 37 :

Citemos estos textos del Levítico:

35: «Si tu hermano empobreciere y no pudiendo valerse, le recibieres como forastero y peregrino y viviere contigo".

36: «No cobres usuras de él, ni más de lo que prestaste. Teme a tu Dios, a fin de que tu hermano pueda vivir en tu casa».

37: «No le darás tu dinero a logro y de los comestibles no le exigirás aumento sobre aquello que le has dado".

Sobre el nuevo Testamento se soporta la condena de la usura en Lucas VI: 34.35:

"¿Y si prestareis a aquellos de quienes esperáis recibir? ¿Qué gracias tendréis? Porque también los pecadores, prestan los pecadores para recibir otro tanto. Prestad no esperando de ello nada y será vuestro galardón".

Igualmente, los autores eclesiásticos aceptan algunos principios del derecho natural para justificar la condena de la usura, se dice que el prestamista no lleva a cabo un verdadero trabajo, ni crea ni transforma ninguna materia, ningún objeto explota el trabajo del prestatario. La iglesia solamente reconoce el trabajo creador como fuente de riqueza y de ganancia.

Pero también los teólogos y canonistas se fundamentan en principios de Aristóteles, quien consideraba que el dinero no puede engendrar dinero. Santo Tomas de Aquino, afirma que solo el dinero puede servir para favorecer los intercambios pero hacerlo rendir por sí mismo es un acto antinatural.

Uno de los más acerbos críticos de la usura fue Martín Lutero, el hecho de haber vivido el momento histórico en que la sociedad burguesa estaba en su etapa final. El inusitado desarrollo del comercio, generó una economía basada en el capital usurario.

En sus libros sobre "El tráfico comercial y la usura", escritos en 1524, se pronunció sobre la actividad de los mercaderes en términos condenatorios. 
"Los mercaderes se entregan en todas partes, entre ellos mismos a tales granujadas a tales depredaciones y a tales actos de bandidaje, contrarios a la doctrina de Cristo, que no debemos extrañarnos de que la providencia divina les condene a perder de nuevo, por unos medios o por otros, estas grandes riquezas mal adquiridas ni de que los mercaderes se veían a su vez atropellados o engañados».?

Respecto de la usura sostenía Lutero:

"Y lo que decimos de los préstamos de dinero, es igualmente aplicable a los préstamos de trigo, de vino y de otros géneros semejantes a éstos. También en estos casos se habla de dos clases de perjuicios imaginarios, pero estos perjuicios no guardan ninguna relación natural con la mercancía, sino que son meros accidentes, y para poder alegarlos como perjuicios hay que probar que existen en la realidad. Si alguien exige su reparación o se la toma por la mano, comete usura e incurre en injusticia [...] Parece como si el mundo no pudiese existir sin usura, sin avaricia, sin orgullo, prostitución, adulterios, asesinatos, robos, blasfemias y toda clase de pecados[...] La usura podrá ser necesaria, pero ¡ay de los usureros![...]». ${ }^{8}$

En la concepción cristiana la condena del pago de intereses, el tiempo es el fundamento de una consideración sustancial. Al respecto Jacques le Goff, sostiene:

«La concepción cristiana del tiempo es quizá más grave, puesto que pone en juego unas estructuras mentales todavía más complejas y más fundamentales, en efecto, en Santo Tomas y otros teólogos y canonistas hayamos este argumento de que, a través de la práctica del interés, se vende el tiempo".

Ahora bien, este no puede ser una propiedad individual, el tiempo únicamente pertenece a Dios.

7 Citado por Carlos Marx, Teoría de la plusvalía, Alberto Corazóm editor, tomo II, Madrid-España, 1974, p.406.

8 Citado por Carlos Marx, op. cit., p. 407. 
"Así la reflexión cristiana se muestra incapaz de alcanzar concepciones económicas, no pudiendo escapar de un marco teológico escrito, sean cuales fuesen los considerables esfuerzos de los pensadores y juristas del Siglo XIII".?

\section{Las deudas y los regímenes liberales}

Algunos autores han afirmado que con la aparición del nuevo estado liberal, el régimen de los derechos de crédito y de la actitud respecto de los deudores fue desarrollada dentro del respeto a la libertad de la persona del deudor.

La protección del deudor y su familia se remonta a las normas contenidas en la Carta Magna, impuesta al Rey Juan de Inglaterra en el siglo XIII.

En materia de deudas la Carta Magna preceptuaba lo siguiente:

Art. 9\%:

«Ni nosotros ni nuestros funcionarios embargaran ninguna tierra o renta mientras los bienes del deudor sean suficientes para pagar la deuda, ni deberán ser embargados aquellos que fueron garantes, mientras el deudor principal es capaz por si mismo de pagar la deuda; y si este fallara en el pago, no teniendo nada con que pagar, deberán los garantes responder por la deuda».

La mayoría de las legislaciones liberales prohiben la pena de prisión por deudas, consagran la protección de ciertos bienes del deudor de la persecución de sus acreedores. Se establecen normas de protección a la familia impidiendo la persecución sobre los bienes del deudor que constituyen un patrimonio familiar, como la casa de habitación (Ley colombiana No 258 de 1996).

Teniendo como herencia el Código napoleónico de 1807, la casi totalidad de las legislaciones latinoamericanas han adoptado normas de protección a los derechos del acreedor y la consagración de procedimientos ejecutivos para obtener la satisfacción de las deudas vencidas.

9 Jacques Le Goff, Mercaderes y banqueros de la Edad media, Ed. Oikos-Tau S.A., Barcelona, 1991, pp. 78-79. 
Los procesos de ejecución se han dividido en dos clases: $1^{\circ}$. Proceso de ejecución singular. $2^{\circ}$. Proceso de ejecución universal.

La ejecución singular o individual, se dirige a la obtención de una sentencia de Juez que ordene al deudor el pago de la obligación para hacerla efectiva sobre bienes que la ley reconoce como embargables.

$\mathrm{La}$ acción ejecutiva individual se soporta sobre el presupuesto del incumplimiento de la obligación singular.

Por su parte, la ejecución universal o colectiva tiene lugar cuando el deudor llegue a un incumplimiento general de sus obligaciones, causado por la imposibilidad patrimonial de responder al pago de todas las obligaciones exigibles.

La ejecución universal o colectiva, se realiza a través del denominado proceso de quiebra, que en algunas legislaciones se extiende, para toda clase de personas sean comerciantes o no.

El presupuesto subjetivo de la quiebra está determinado por una persona natural o jurídica, con un patrimonio susceptible de ejecución.

Cuando el sujeto pasivo de la quiebra lo constituye el comerciante, el procedimiento quebrario se aplica al comerciante activo, retirado e inclusive al fallecido.

El presupuesto objetivo de la concursalidad está señalado caprichosamente por los legisladores. Algunos consideran como presupuesto la insolvencia, entendiéndose como el estado patrimonial del deudor que se manifiesta externamente como una excedencia de pasivos frente a una deficiencia de activos; para otros, el presupuesto que autoriza la apertura de la concursalidad está dado por la "cesación de pagos", situación que se refleja en la imposibilidad de la caja del deudor para cancelar oportunamente las obligaciones.

Los estatutos quebrarios tomados del Código napoleónico, mantenían la severidad y crueldad para con el deudor, propias del derecho estatutario de la edad media. Solo a mediados del Siglo XX, el derecho quebrario produjo un cambio en la teleología concursal, se orienta el proceso quebrario a la protección del crédito en forma indirecta, sin penalidad a la persona del fallido, se toma como objetivo prioritario de protección el ente que emerge después de la primera guerra mundial, como lo es la empresa, de inconmesurables repercusiones en el campo público, económico y social de los países.

Aunque aún subsisten en muchos países de Latinoamérica la huella del derecho medieval en los procesos de quiebra, su esquema filosófico se caracteriza por ser un proceso de carácter penalizador vengativo. 
Dictado el auto de apertura a quiebra, el fallido sufre de inmediato las siguientes consecuencias:

a) Queda separado de la administración y dirección de sus bienes embargables.

b) Se produce la incautación de todos los libros, papeles de comercio y correspondencia.

c) Se decreta el arraigo judicial, privándolo de la libertad de locomoción.

d) Se le inhabilita para ejercer el comercio.

e) Se decreta el embargo y secuestro general de todos los bienes embargables.

f) Y en algunas legislaciones se estipula la aprehensión del fallido persona natural, tratándose de sociedades, la detención física se realiza sobre el representante legal de la sociedad falente.

La evolución de la economía, la masificación del comercio, la importancia y necesidad de protección de la empresa, condujo a los juristas y legisladores a crear instituciones preventivas de la quiebra, a fin de evitar este tortuoso proceso, que no había producido ningún beneficio al crédito, ni a los acreedores, ni había logrado el saneamiento de las finanzas.

A comienzos del siglo XX, Bélgica acoge la institución del concordato preventivo, como un procedimiento concursal para evitar el proceso de quiebra. Posteriormente esta figura, se acoge en la mayoría de los países europeos.

En algunos países de América Latina como Argentina, Brasil, Colombia y Ecuador, se recoge en sus legislaciones la figura del concordato o concurso preventivo.

Colombia en 1969 introduce en su legislación positiva el proceso concordatario, institución que fue objeto de algunas reformas como las contempladas en el Decreto Ley No 350 de 1989, Ley № 222 de 1995.

Actualmente se suspendió el concordato por cinco (5) años, mediante la Ley No 550 de 1999, para incorporar al sistema la denominada «intervención económica" para los empresarios que se encuentren en el estado de cesación de pagos. Esta figura desjudicializa y desprocesaliza íntegramente la institución concursal para entregar todo el procedimiento y la elaboración de propuesta de arreglo del deudor empresario con sus acreedores a un "promotor", persona natural, elegida de una lista que confor- 
ma las distintas entidades de vigilancia de las sociedades o las Cámaras de Comercio.

La Ley No 222 de 1995, consagró la figura del concordato para la persona no comerciante, normativas vigentes que fueron ratificadas por la Honorable Corte Suprema de Justicia, en sentencia de acción de tutela de 16 de Diciembre de 1999.

Después de muchos debates académicos, el legislador colombiano adquirió conciencia que el proceso de quiebra era totalmente inoficioso, improcedente, que causaba más daño a los acreedores y al deudor que beneficios, que los procesos de quiebra se eternizaban en los anaqueles de los juzgados y que el beneficiario de todo este sistema era el síndico. Por eso Colombia es el primer país de América Latina y del Caribe que eliminó de su organización jurídica el mal denominado proceso de quiebra.

Los fracasos o incumplimientos de los concordatos preventivos o de la reestructuración de las deudas de los deudores, se conducen a través de una liquidación obligatoria, manejada jurisdiccionalmente por un ente administrativo, de orden nacional, denominado Superintendencia de Sociedades.

En cuanto al proceso de ejecución singular se mantienen en nuestros páses latinoamericanos la institución de las medidas cautelares de embargo y secuestro de los bienes del deudor.

Medidas cautelares que se han venido ejecutando dentro del proceso principal, con la finalidad de garantizar el "perinculo in mora».

Las medidas provisorias se hacen a escondidas del deudor, sin la garantía de un debido proceso, muchas veces con la espectacularidad del "bonorum cessio» de la edad media, con embargos y secuestros de bienes, sin límite del derecho de persecución del acreedor, sobre bienes indispensables al desarrollo de la personalidad del deudor, o a la protección de la familia, etc.

Con sobrada razón, el ilustre procesalista mexicano Humberto Briceño Sierra, en el pasado Encuentro del Instituto Panamericano de Derecho Procesal realizado en Trujillo-Perú en 1998, sostuvo que, tal como están reguladas la medidas cautelares en nuestros Códigos de Procedimiento Civil, son absolutamente antiprocesales.

La mayoría de las legislaciones consagran en sus códigos de enjuiciamiento la forma de rematar los bienes del deudor perseguido judicialmente. Hecho el avalúo judicial, los bienes se sacan a la subasta pública por el $70 \%$ del valor del avalúo, fracasada la primera almoneda, el bien sale a remate por el $50 \%$, y si ésta también llegare a fracasar, la ley con- 
templa la posibilidad que se lleve a la subasta pública por el $40 \%$ del avalúo practicado.

La demora en los procedimientos judiciales, el manejo de los avalúos, la formación de grupos dedicados al remate de bienes aprovechándose de la permisibilidad de las leyes, ha sido otro mecanismo de despojo no solo del patrimonio del deudor sino de su propia dignidad. La ley no puede seguir amparando este tipo de injusticias ni puede convertirse en alcahueta para que las riquezas se trasladen tan cómodamente en beneficio de los más poderosos.

En algunos países se ha institucionalizado como mecanismo de presión para el cobro de sumas de dinero adeudadas a usureros y prestamistas, la utilización de personajes estrambóticos, disfrazados de animales, de payasos o en trajes ceremoniales, quienes se colocan en la puerta de entrada del domicilio del deudor, con un llamativo aviso o estrafalario maletín con la leyenda de «deudor moroso». El personaje cobrador permanecía día y noche y solo cuando el avergonzado deudor pagaba la deuda podía liberarse de su implacable acreedor. Este oprobioso sistema de cobro no era más que la réplica moderna del denominado «bando», utilizado en la edad media para estigmatizar al deudor.

En mi país, existían empresas organizadas conforme a la ley y autorizadas por las autoridades para la prestación de este servicio de cobradores. Los mismos abogados, antes de adelantar ante la jurisdicción el proceso de ejecución, utilizaban este mecanismo de efectividad sorprendente.

Solo por decisión de la Corte Constitucional en una acción de tutela (Amparo en el derecho argentino) se desterró esta perversa práctica de cobro extrajudicial, por considerar que violaba flagrantemente los derechos fundamentales del deudor a la intimidad y al buen nombre.

$\mathrm{Si}$ este sistema de cobro nos parece infamante, que atenta contra la dignidad de la persona del deudor, aún no hemos podido erradicar las aberrantes prácticas que han organizado el poderoso sistema financiero de colocar en una central de datos el nombre de los deudores morosos, aun habiendo cancelado sus obligaciones. Cuando se trató de prohibir en mi país este mecanismo indigno, el poder de los banqueros fue mucho más contundente que las razones de derecho.

Y en este tortuoso camino de humillaciones y vejámenes al deudor, no faltan los mecanismos de hostigamiento y presión sicológica como los de empapelar las paredes de los edificios o conjuntos residenciales donde habita el deudor publicando su situación de deudor en mora o los utiliza- 
dos sistemas de publicar en los inmuebles sujetos al régimen de propiedad horizontal la lista de los deudores morosos.

Bien lo señaló la Corte Constitucional colombiana en sentencia No T340 de 1993, con ponencia del doctor Carlos Gaviria al condenar estos sistemas "persuasivos" de cobro:

"No es aceptable que con estas situaciones se pretenda desnaturalizar figuras como la del requerimiento particular o privado, que permiten, en muchas ocasiones, evitar con anticipación el trámite judicial, al acudir directamente a los deudores para lograr la satisfacción de la acreencia. No puede aceptarse que en ejercicio de la facultad de cobro, sea posible violentar los derechos mínimos de cualquier persona, negándole la posibilidad de controvertir la exigibilidad de las obligaciones que se persiguen; mucho menos, atentando contra el libre ejercicio de sus derechos fundamentales".

Tema de controversia es el tratamiento que los Estados le han venido dando a los deudores de deudas fiscales. El soberano fisco, la política alcabalera de estos empobrecidos países, parecen monolitos de épocas prehistóricas en los que el hombre no tenía ningún reconocimiento de sus derechos como persona humana.

Aun se conservan en algunas legislaciones la pena privativa de la libertad por deudas fiscales. En Colombia el retenedor del impuesto al valor agregado IVA, o de la retención en la fuente que no pague oportunamente a la Dirección de impuestos y aduanas nacionales (DIAN), se judicializa su conducta a través de la figura delictual del peculado por apropiación, con detención de la persona física, sin beneficio de excarcelación.

La creación perversa de la jurisdicción coactiva en la cual el juez de la causa en el mismo acreedor atenta contra los principios universales del debido proceso, y del principio fundamental reconocido como es la imparcialidad del juez; todo lo cual conspira contra la persona del deudor y del irrespeto a su dignidad.

\section{Los deudores soberanos o los pobres países deudores}

La atención de este trabajo se ha dirigido precedentemente a estudiar la persona del deudor, como persona humana. 
La configuración geográfica, económica y política de este planeta de infortunios, nos obliga a detenernos un poco para estudiar los estados nacionales como deudores de un sistema financiero mundial, que como máquina infernal ha venido devorando el presente y futuro de los países que pertenecen al denominado bloque del tercer mundo, al cual pertenecemos con el África y parte de Oceanía.

Los países pobres, debido a sus débiles estructuras financieras, se vieron en la necesidad de recurrir a préstamos con los bancos internacionales y con los estados ricos como Estados Unidos, Japón, Alemania, Gran Bretaña.

Para garantizar el pago de las deudas de los países pobres al sistema bancario internacional y a los estados prestamistas, se creó el Fondo Monetario Internacional (FMI), que se ha convertido como el policía de la deuda global.

A partir de los años setenta, los préstamos de los países pobres se aumentaron descontroladamente y se flexibilizaron las exigencias para otorgarlos.

La organización de los países productores de petróleo OPEC, debido al alza del petróleo, canalizaron en los años setenta todos sus ingresos hacia los bancos de los Estados Unidos y de Europa. La excedencia de dinero en los bancos los obligó a ofrecer irresponsablemente préstamos a los países pobres, sub-desarrollados, para colocar los dineros y generar los intereses que debían pagar a sus depositantes.

La urgencia de colocar el dinero, se canalizó hacia los países pobres, a quienes se les concedieron multimillonarios préstamos para la compra de armas; financiación de mega proyectos de infraestructura, como la construcción de autopistas, represas, construcciones de aeropuertos, ferrocarriles, metros, muchos proyectos sobrevalorados por las altas comisiones entregadas a los intermediarios; por el pago de participaciones a los funcionarios corruptos; por la sobrefacturación de los materiales y equipos. Muchos de los megaproyectos financiados eran totalmente inviables, y bien lo sabían los banqueros prestamistas.

Miles de millones de dólares fueron prestados a gobiernos represivos para fortalecer sus inventarios armamentistas o para realizar escandalosos proyectos en las que obtenían millonarias ganancias.

Cuatro factores incidieron para incrementar las deudas de los países pobres: a) Préstamos descontrolados; b) Un indebido modelo de desarrollo; c) La concepción de los gobiernos de turno; d) Destinación de los dineros a empresas improductivas. 
Según el Banco Mundial los países del tercer mundo han pedido préstamos por la suma de 1935 billones de dólares y han devuelto 2237 billones de dólares entre los años de 1972 y 1992 . No obstante, todavía los países del tercer mundo deben 1.700 billones de dólares a los países del norte, a los bancos comerciales y a los organismos financieros multinacionales.

En el año 2000 la deuda consolidada de América Latina y el Caribe sumaba 750.835 millones de dólares. De 1991 al año 2000, la deuda se incrementó en el $61 \%$. Del total de la deuda los países más endeudados son Brasil, Argentina y México que sumados, representan el $72 \%$ de la totalidad de la deuda desembolsada al año 2.000.

Veamos el desarrollo de la deuda externa bruta desembolsada en América Latina y el Caribe entre 1991 al año 2000:

América Latina y el Caribe. Deuda externa bruta desembolsada ${ }^{10 a}$

\begin{tabular}{|c|c|c|c|c|c|c|c|c|c|c|}
\hline \multirow[t]{3}{*}{ País } & \multicolumn{10}{|c|}{ (en millones de dólares) } \\
\hline & 1991 & 1992 & 1993 & 1994 & 1995 & 1996 & 1997 & 1998 & 1999 & $2000^{b}$ \\
\hline & 460952 & 479014 & 527303 & 562830 & 516919 & 638519 & 663090 & 745360 & 759085 & 750855 \\
\hline Argentina & 61334 & 62766 & 72209 & 85656 & 98547 & 109756 & 124696 & 140489 & 144657 & 147000 \\
\hline Bolivia ${ }^{c}$ & 582 & 3784 & $3 \pi 7$ & 4216 & 4523 & 4366 & 4234 & 4655 & 4574 & 4400 \\
\hline Brasil & 123811 & 135949 & 145726 & 148295 & 159256 & 179935 & 199998 & 241644 & 241468 & 235000 \\
\hline Gile & 17319 & 18964 & 19665 & 21768 & 20026 & 2979 & 26701 & 31691 & 34167 & 36000 \\
\hline Colombia & 17335 & $172 \pi$ & 18908 & 21855 & 24928 & 29513 & 32036 & 35696 & 35972 & 36000 \\
\hline Cost Rica & 3992 & 4056 & 4011 & 3818 & 3889 & 3376 & 3290 & 3500 & 3700 & 4000 \\
\hline Guba & 6500 & 6400 & 8785 & 9083 & 10504 & 10465 & 10146 & 11200 & 11040 & 11100 \\
\hline Earador & 12802 & 12795 & 13631 & 14589 & 13934 & 14586 & 15099 & 16400 & 16282 & 14255 \\
\hline EISalvador ${ }^{\mathrm{c}}$ & 2000 & 2343 & 1976 & 2056 & 2168 & 2517 & 2689 & 2631 & 2810 & 2750 \\
\hline Gunemalh & 2614 & 2520 & 2323 & 2644 & 2936 & 3033 & 3210 & 3619 & 3945 & 3900 \\
\hline Guyana & 1873 & 2054 & 2062 & 2004 & 2058 & 1537 & 1514 & 1500 & 1196 & 1250 \\
\hline Haiúc & 899 & $8 / 2$ & 866 & 875 & 902 & 914 & 1025 & 1100 & 1165 & 1200 \\
\hline Honduras & 3441 & 3590 & 3850 & 4040 & 4242 & 4121 & 4062 & 4404 & 4728 & 4000 \\
\hline Jamaica & 3874 & 3678 & 3687 & 3652 & 3452 & 3232 & 3278 & 3300 & 3050 & 3200 \\
\hline Mériód & 117000 & 116501 & 130524 & 139818 & 165600 & 157200 & 149000 & 161300 & 167500 & 163200 \\
\hline Nicaragua $^{c}$ & 10313 & 10792 & 11987 & 11695 & 10248 & $60 \% 4$ & 6001 & 6287 & 6499 & 6650 \\
\hline Panamás & 3699 & 3548 & 3494 & 3663 & 3938 & $50(9)$ & 5051 & 5180 & 5412 & 5550 \\
\hline Paraglay & 1666 & 1249 & 1254 & 1271 & 1439 & 1434 & 1473 & 1599 & 2108 & 2000 \\
\hline Peú & 20787 & 21409 & 27489 & 30392 & 33515 & 33805 & 28508 & 29477 & 27966 & 27600 \\
\hline Rep.D & 4614 & 4413 & 4563 & 3946 & 3999 & 3807 & 3572 & 3537 & 3536 & 3700 \\
\hline Trinidady Tobago & 2438 & 2215 & 2102 & 2064 & 1905 & 1876 & 1541 & 1430 & 1511 & 1550 \\
\hline Unuguay & 2949 & 3392 & 3578 & 4251 & 4426 & 4682 & 4754 & 5195 & 5180 & 5550 \\
\hline Veneruda & 36000 & 38447 & 40836 & 41179 & 38484 & 34222 & 31212 & 29526 & 30619 & 30800 \\
\hline
\end{tabular}

10 Fuente: CEPAL, sobre la base de cifras oficiales a Incluye la deuda con el Fondo Monetario Internacional 
Tanto los países prestamistas y los bancos multinacionales han designado al Fondo Monetario Internacional como el auditor que garantice el pago de las deudas externas de los países del tercer mundo.

El Fondo Monetario Internacional (FMI) cumple su misión por medio del programa denominado de «estabilización» $\mathrm{y}$ «ajuste estructural» para lo cual se les obliga a estos países deudores a manejar los presupuestos de gastos y de inversión. Obligando a los países a reducir los déficit de los presupuestos mediante políticas neoliberales de despidos masivos de trabajadores de las entidades gubernamentales, privatización de las empresas estatales, aumento de la exportaciones de materias primas, aumento de tasas y contribuciones, todo con el fin de obtener la bonanza de las tesorerías que permitan atender el pago de la deuda y sus intereses.

Las consecuencias más graves de toda esta política del Fondo Monetario Internacional la sufren los países pobres, especialmente el África aunque la deuda es menor que la de América Latina, su capacidad de pago es totalmente reducida.

Las estrategias del Fondo Monetario Internacional para incrementar las exportaciones de materias primas de los países subdesarrollados, han traído como consecuencia la devastación de los bosques húmedos con los efectos ambientales de la alteración climática, la explotación de minas con materias contaminantes que han deteriorado considerablemente el medio ambiente de estos países pobres.

La sobre explotación de los recursos naturales para poder atender el pago de la deuda externa de estos países tercermundistas, ha afectado el equilibrio ecológico poniendo en peligro la biodiversidad y el derecho fundamental que tiene toda persona a disfrutar de un medio ambiente sano.

Para atender el pago de los altos intereses, los países han tenido que recurrir a nuevos préstamos, convirtiéndose así en unos irremediables deudores, en que el anatocismo y la usura se han configurado como elementos constitutivos de este sobre endeudamiento, que mutilará para siempre el desarrollo futuro de los países deudores y compromete a las generaciones futuras.

\section{b Cifras preliminares}

c Deuda externa pública

d La deuda pública excluye la inversión en valores gubernamentales por parte de los no residentes. 
El pago de los intereses entre 1990 y 1995 de veinte (20) países de América Latina y el Caribe ascendió a 174.600 millones de dólares.

Toda esta situación ha generado una inestabilidad en las economías de los países deudores, un incremento de la miseria y la pobreza de los países tercermundistas, una destrucción de la producción agrícola campesina, un deterioro considerable del medio ambiente. Las políticas del Fondo Monetario Internacional de exigir la privatización de las empresas del Estado ha generado una nueva fuente de corrupción incontrolable, concentración de la riqueza en grupos financieros internacionales, una mayor ingerencia de los acreedores en los destinos políticos de estos países deudores, un desempleo aterrador y una disminución de acceso a los servicios públicos.

En el informe anual del Presidente del Banco Interamericano de Desarrollo BID correspondiente al año 2000, señala que:

«Se calcula que en América latina hay entre 180 y 200 millones de personas que viven en la pobreza, o sea entre el $37 \%$ y el $40 \%$ de la población. Durante los años 90 la pobreza se redujo solo tres puntos porcentuales. Esta leve disminución se debió al progreso en ese sentido en Brasil, Chile, Costa Rica, Panamá y República Dominicana. Sin embargo, según los indicadores disponibles hasta 1997 en México y Venezuela la pobreza aumento. Debido a la falta de sistemas adecuados de protección social en la mayoría de los países de la región, las crisis económicas han sido la causa principal que ha impedido una reducción más rápida y sostenible de la pobrezam. ${ }^{11}$

\section{La indexación de las deudas}

El sistema de economías inflacionarias en los países del tercer mundo, el envilecimiento de la moneda por factores devaluacionistas, llevó inicialmente a la jurisprudencia a fijarles a las deudas un valor constante, mediante el sistema denominado de indexación o ajuste de la deuda conforme a las variaciones de los índices de los precios al consumidor. Era la

11 Informe Anual del Presidente del Banco Interamericano de Desarrollo BID, presentado a la Asamblea General de Gobernadores realizada en Santiago de Chile en el mes de marzo del año 2001. 
manera como se hacía justicia al deudor, para que su deuda se mantuviera a valor presente, sin que el acreedor se beneficiara injustamente de los factores inflacionarios, generando un enriquecimiento indebido.

Estos falsos principios de equidad, determinaron que en ciertas legislaciones se estableciera un sistema jurídico-económico que le permitiera al acreedor mantener los valores reales de lo prestado, a fin de que se le garantizara la recuperación por el valor presente a la fecha de pago del dinero entregado en préstamo a su deudor.

Pero adicional a esta indexación de la deuda, también se le ha reconocido al acreedor el pago de los intereses de plazo o los correspondientes intereses moratorios, lo cual convertía a la deuda en sumas que en muchos casos se tornaban impagables.

Durante muchos años ha imperado el sistema descrito, pago de la deuda indexada más los correspondientes intereses, desconociendo el principio que el interés es el valor del resarcimiento por pérdida del valor adquisitivo de la moneda; en esta rueda de la fortuna se expoliaron a los deudores en beneficio de los acreedores, especialmente de los acreedores institucionales como los bancos, corporaciones y demás entidades de crédito.

En las economías pobres como las nuestras, dentro de un marcado sistema neoliberal y con el supuesto fin de beneficiar a las clases trabajadoras o de escasos recursos, para que tuvieran el derecho a adquirir una vivienda se concibió un sistema de créditos a largo plazo, garantizándole a las entidades financieras la recuperación de los préstamos a valores de adquisición constantes.

En Colombia, mediante la expedición de decretos autónomos de 1972, se consagró el sistema de financiación de vivienda a largo plazo, a través de las unidades de valor adquisitivo constante UPACS, equivalente al valor de la moneda de circulación nacional, incrementado con los índices de inflación que reportara el DANE (Departamento Nacional de Estadística), conforme a la variación mensual de los índices de precios al consumidor.

El sistema en sus comienzos generó beneficios a los adquirentes de vivienda, propició un incremento en el sector de la construcción, lo cual generó un aumento en el empleo de mano de obra y un desarrollo de las empresas que dependen de la construcción.

Las financiaciones de crédito para obtener vivienda estaban estructuradas sobre cuotas variables, a largo plazo, en que jugaba la inflación como factor determinante en la liquidación de las cuotas mensuales correspondientes. 
Los préstamos a largo plazo atados a la inflación que hacían las corporaciones de ahorro y vivienda no soportaron la carga financiera de los depósitos a corto plazo con el reconocimiento y pago de intereses comerciales, cuyas tasas se dispararon a límites incalculables de más del $70 \%$ de interés real.

Debido a la distorsión entre la colocación de los créditos a largo plazo indexados y la captación de recursos a corto plazo con el pago de intereses comerciales, llevó al sector financiero a presionar al Banco de la República para que las unidades de poder adquisitivo constante UPAC, no estuvieran atadas a la inflación, sino al verdadero costo del dinero en el mercado. Por decisión del Banco emisor el sistema que garantizaba el poder adquisitivo de las deudas para vivienda se transformó sustancialmente, atando el UPAC, al valor de los intereses comerciales, con esta decisión quedaron los préstamos de vivienda conforme al valor de los intereses reconocidos en el mercado financiero. A partir de 1995, año en que se modificó el sistema, las Corporaciones de ahorro y vivienda otorgaron préstamos a los constructores de vivienda, de locales comerciales, de toda clase de inmuebles, bajo el nuevo sistema de liquidación de los depósitos con los intereses comerciales de captación de créditos, de depósitos a término fijo más el margen de intermediación financiera que en Colombia asciende al $10 \%$.

Los adquirentes de vivienda se subrogaban en las deudas de los constructores o adquirían directamente los créditos con las Corporaciones para la compra de inmuebles con financiación a largo plazo, bajo la modalidad del sistema UPAC.

A partir del año 1996, los intereses comerciales subieron considerablemente, lo cual afectó a los deudores del sistema UPAC, generando situaciones en que no podían atender el pago de la deuda, debido a las altísimas cuotas que liquidaba mensualmente el sistema; pero igual que el alza de las cuotas de pago, las deudas se fueron incrementando hasta llegar a límites inconcebibles que superaban el valor de la vivienda, no obstante los abonos realizados por largos años. La situación eclosionó en los años 97 y 98 por la cesación de pagos de una mayoría de los deudores del UPAC.

La injusticia del sistema, la implacable actuación de las entidades financieras contra la persona del deudor, con la instauración masiva de juicios de ejecución, llevó finalmente al desespero de los deudores entregando los inmuebles objeto de la garantía a las corporaciones de ahorro y 
vivienda. Esto, bajo la modalidad de la «dación en pago" por precios irrisorios a la pérdida de la vivienda, a través de los remates judiciales, siendo despojados de sus bienes, de sus viviendas con afectación de todo el entorno familiar.

Los más afectados dentro de este oprobioso sistema, fueron las clases menos favorecidas, quienes debido a la recesión económica del año 1998 a la fecha, los niveles de desempleo han llegado a la alarmante cifra del $25 \%$ que trajo como consecuencia la suspensión de los pagos a las corporaciones acreedoras. Los procesos ejecutivos hipotecarios se instauraron masivamente, no obstante el beneficio de la ley judicial para efectuar los remates de los bienes hipotecados, no se obtuvieron las posturas necesarias y las corporaciones remataron por el $40 \%$ del avalúo de los bienes quedando saldos insolutos a cargo de los desfallecidos deudores.

Como todo problema económico masivo, generó un problema social que aglutinó las fuerzas dispersas de los empobrecidos deudores a través de ONG que presionaron al gobierno para que desmontara el sistema sin haber obtenido ninguna respuesta. Trasladaron sus inquietudes a los estrados del Congreso sin que los representantes del pueblo, produjeran los cambios urgentes que quería el sistema. El último recurso lo hicieron ante la Corte Constitucional demandando la inconstitucionalidad de las normas por cuanto atentaban contra los preceptos constitucionales, especialmente contra el derecho fundamental a tener una vivienda digna.

La Corte Constitucional de Colombia, mediante providencia de 27 de mayo de 1999 declaró inconstitucional el Art. 16 de la Ley № 31 de 1992, la cual le concedía la atribución al Banco de la República a determinar el valor de la Unidad de Poder Adquisitivo Constante, reflejando los movimientos de la tasa de interés en la economía.

Posteriormente la misma Corte Constitucional declaró inexequible la totalidad de los artículos del Decreto No 663 de 1993 que estructuraba el sistema del Poder Adquisitivo Constante.

De esta suerte el único que respondió a los clamores de los deudores fue la Corte Constitucional Colombiana, que en cumplimiento de lo consagrado en la Constitución, protegió los derechos fundamentales de la persona de los deudores, en su dignidad amparados dentro del Estado Social de Derecho, promulgado en la Constitución del año de 1991. 
VIII. El pasaporte al mundo de la intimidad

Antes de la II Guerra Mundial, solo los ricos tenían acceso al crédito. Las grandes mayorías, los pobres, la clase media, eran definitivamente privadas de acceso al crédito.

Los bancos comenzaron a surgir con clientes adinerados. Con cierta razón alguien sostenía que los dos elementos esenciales para que una institución bancaria tenga éxito son: primero el dinero de los demás y segundo prestarle a los ricos.

Los bancos no prestan a los asalariados y campesinos. Los créditos pequeños, los créditos de consumo se hacían en tiendas de abarrotes de barrios, sin interés dentro de una relación personalizada y de confianza.

Cuando una persona de la clase media requería de liquidez recurría al crédito que concedían los montepíos o casas de empeño entregando reliquias de familia o joyas a los usureros que prestaban a intereses exorbitantes y con represalias físicas y morales en la persona del deudor en caso de incumplimiento.

En el año de 1950, el director de una pequeña empresa financiera Frank Mc Namara, inventó el "Club de los comensales», mediante el cual, una escogida clientela tenía derecho a comer a crédito en veintidós restaurantes New Yorquinos, cobrándole al usuario y al establecimiento una comisión por las facturas pagadas. Así nació la primera tarjeta de crédito en el mundo: "Diners Club".

En 1958 la American Express empezó a vender su tarjeta del mismo color del dólar, verde, para obtener el crédito en la compra de tickets aéreos, pago de hoteles y hospedajes. La tarjeta de crédito comenzó a conquistar los mercados del mundo.

En 1980 la American Express contaba con mas de diez millones de tarjeta-habientes en todo el mundo. La American Express debido a su expansión decidió convertirse en un importante banco internacional con servicios financieros directos mediante los sistemas de comunicación por cable.

Los bancos ingresaron a este fabuloso mundo de la tarjeta de crédito, se interesaban más por los intereses que pagaban los clientes que por el pago de las facturas y por las comisiones de los establecimientos afiliados. El Bank of America y el Chasse emitieron sus propias tarjetas, el Chasse perdió millones de dólares debido a la mala administración.

Bancos de California inventaron la Master Card. El Bank of America entregó la administración de las tarjetas de crédito a una entidad confor- 
mada por bancos en la cual pudo conquistar los mercados internacionales, para impulsar lo que conocemos con el nombre de VISA, palabra mágica que permite el ingreso al mundo inacabado del consumo.

La tarjeta VISA y la Master Card acapararon el mercado mundial, ayudados por el triunfo de las computadoras donde se procesaban millones y millones de datos y cargos y abonos a las cuentas de los establecimientos afiliados y a las tarjetas de los beneficiarios en un solo día, en cualquier parte del mundo.

La magia de la tarjeta de crédito, el desarrollo tecnológico de los computadores lograron el milagro de conceder créditos a millones de personas, sin conocer a los clientes, sin la exigencia de entrega de garantías tradicionales, sin la utilización de contingentes de trabajadores. Las máquinas ordenadoras lo hacian todo. Se rompieron todas las fronteras, se podía obtener crédito en cualquier parte del mundo; toda la concepción del crédito, del verbo creer estaba confiado a un computador, quien tenía en su memoria los mecanismos de saber cuando se podía utilizar la tarjeta para obtener los créditos.

La mayor automatización se logró a través de la transferencia electrónica de fondos que permiten prescindir totalmente de la persona humana, la operación se hace a través de los cajeros automáticos, las compras se puede realizar a través de un terminal de computador instalado en un almacén, que instantáneamente carga la operación a la tarjeta de crédito.

Pero este increíble mundo del consumo, esta masificación del crédito, esta relación despersonalizada del deudor y el acreedor no deja resueltas las inquietudes respecto de la protección de los derechos de la persona del deudor y del respeto al derecho a la intimidad.

El deudor tarjeta-habiente, queda totalmente expuesto a que su derecho a la intimidad sea íntegramente vulnerado por los operadores de los sistemas informáticos de las multinacionales dueñas de las tarjetas de crédito. El banco acreedor de la tarjeta de crédito, puede penetrar al secreto e inviolable mundo de la intimidad de la persona del deudor porque conoce fehacientemente todas las actividades que desarrolla en todos los rincones del planeta, sabe qué viste, qué restaurantes visita, en qué parte del mundo se encuentra, qué empresas de aviación utiliza y hasta conoce al instante, en qué lugar privado de su intimidad se encuentra.

La monstruosidad de los computadores que reciben a cada instante la información de los cargos de cuenta de los consumidores tarjeta-habientes acumulan en sus bancos de datos una información acerca de la persona del 
deudor que puede constituirse en el mayor peligro contra la dignidad de la persona humana, para la libertad individual para la vigilancia de los disidentes políticos de los gobiernos autoritarios.

En el libro Los bancos y la crisis mundial de Anthony Sampson se relata el siguiente episodio:

«En 1971 se reunió en Washington un grupo de especialistas en informática y seguridad, al objeto de contestar al siguiente problema hipotético que se les propuso: "Supongamos que reciben ustedes el encargo de proyectar un sistema para el control de todos los ciudadanos, así como de los turistas, dentro de las fronteras de la Unión Soviética. Tal sistema no debe ser ni demasiado indiscreto ni demasiado visible. ¿Cuál sería su decisión?». Después de pensarlo durante dos días, el grupo de expertos decidió que no era posible idear nada mejor que la Transferencia Electrónica de Fondos». ${ }^{12}$

Por lo visto, la tarjeta de crédito constituye la "VISA" para ingresar a ese secreto y vulnerable mundo de la intimidad y de la libertad.

\section{A manera de reflexión}

Nada se puede concluir, en nuestras manos no está el poder de cambiar este mundo de injusticias, solo nos queda invocar a manera de reflexión estos escolios como un acto de iniciación al rescate de la dignidad del deudor.

10- El siglo XIX, fue el siglo de las libertades.

El siglo XX, fue el siglo de las seguridades.

El siglo XXI, será el siglo en que se garanticen la protección y defensa de los derechos humanos, con prevalencia sobre cualquier otro derecho de contenido económico o patrimonial. El siglo XXI debe ser el siglo de rescate de la dignidad de la persona humana.

$2^{\circ}$ - Los derechos fundamentales deben constituir derechos-función de los estados democráticos.

12 Anthony Sampson, Los Bancos y la crisis mundial, Editorial Grijalbo, España, 1993 , p. 258. 
30- Dentro de esta teleología, los estados deben dictar estatutos que garanticen los derechos de los acreedores y deudores dentro de una correlación de fuerzas jurídicas iguales, para restablecer el equilibrio de la balanza de la justicia, que siempre se ha inclinado a favor del acreedor en detrimento de la dignidad de la persona del deudor.

40- Las nuevas realidades económicas, las facilidades dadas por una economía de consumo, que incitan y permiten el acceso fácil al crédito, la masificación de los endeudamientos y de los procesos de cobro judicial han colapsado las caducas estructuras de los juicios ejecutivos. Esto obliga a idear nuevas instituciones o sistemas de ejecución singular que garanticen al acreedor la recuperación de sus deudas, dentro de los límites de respeto a la dignidad de la persona humana del deudor se deben eliminar de las legislaciones positivas las denominadas acciones cautelares de embargo y secuestro para transformarlas en procesos que le garanticen al acreedor el derecho de instar y al deudor el derecho de defensa.

Debe eliminarse de las legislaciones positivas las ventas forzadas de los bienes del deudor por valores inferiores a los avalúos practicados, pues ello conlleva el empobrecimiento del deudor y el enriquecimiento de su acreedor o de terceros que se dedican a fortalecer sus fortunas a través de almonedas judiciales.

$5^{\circ}$ - Debe prohibirse por las legislaciones, la inclusión de los nombres de los deudores en bancos de datos, por términos indefinidos, pues ello constituye una sanción infamante que atenta contra el derecho fundamental a la intimidad y al "babeas data».

60-Se ha demostrado a lo largo de la historia el fracaso del proceso de ejecución universal de la quiebra; por consiguiente, debe eliminarse este proceso para crear un nuevo proceso concursal que permita la liquidación ordenada de las empresas falentes.

70- Luchar por la creación de un Tribunal Internacional, para el rescate de la dignidad de los pueblos deudores pertenecientes al denominado tercer mundo, a fin de resolver sobre la situación de insolvencia de los países deudores; declarar las nulidades o anulaciones parciales o totales de las deudas adquiridas con los bancos internacionales y los países ricos, la consideración de los niveles de endeudamiento y la obligación de los acreedores de resarcir el daño ecológico producido por el servicio de la deuda externa.

$8^{\circ}$.- Establecer en el derecho positivo, la responsabilidad objetiva de los bancos, corporaciones o entidades profesionales operadores de crédi- 
to, cuando los créditos se hayan otorgado en forma irregular, irresponsable o indebidamente, que lesione la persona y el patrimonio del deudor, $y$ la consiguiente expedición de procedimientos que resuelvan sobre la responsabilidad de los acreedores ágiles, breves y prevalentes sobre cualquier otro tipo de procesos. 